\title{
Managing Metabolic Risk Factors of Non-Communicable Diseases: A Field Trial
}

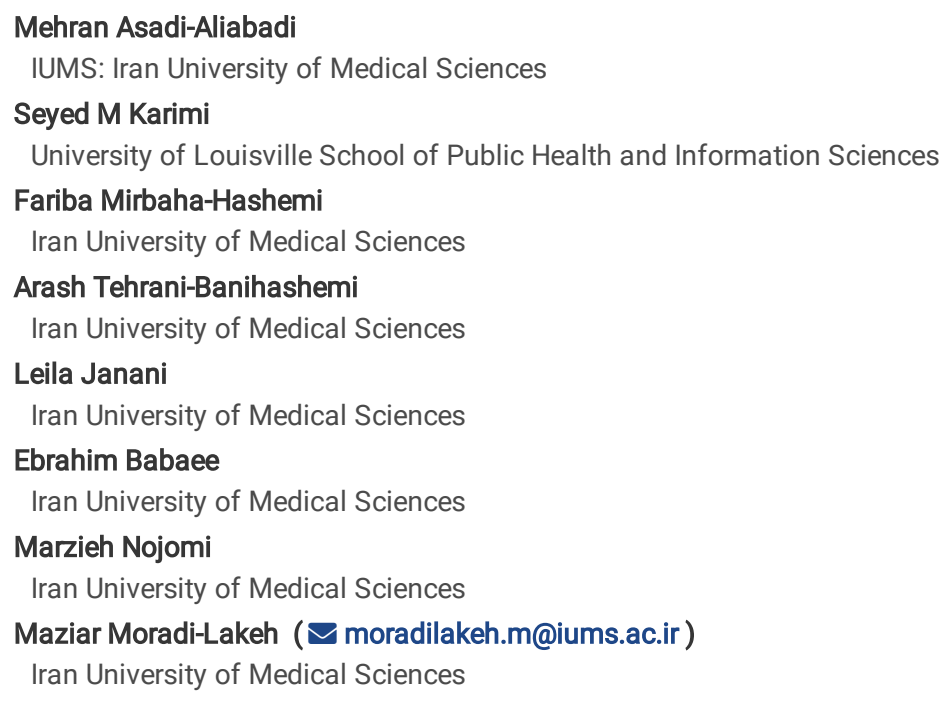

\section{Research Article}

Keywords: metabolic risk factors, non-communicable diseases, Iran, pay-for-performance

Posted Date: January 17th, 2022

DOI: https://doi.org/10.21203/rs.3.rs-1254518/v1

License: @) (1) This work is licensed under a Creative Commons Attribution 4.0 International License. Read Full License 


\section{Abstract}

Background: Non-communicable diseases can be controlled and managed by reducing their associated metabolic risk factors. In this study, a set of intervention packages were designed to reduce the prevalence of metabolic risk factors in the community by motivating non-physician health workers.

Methods: A field trial study was conducted in 4 districts of Iran. Thirty-two community health centers were randomly selected in the districts. A survey of 30 to 70-year-old participants in each community health center was conducted to measure baseline metabolic risk factors. The intervention packages focused on improving hypertension, hyperlipidemia, obesity and overweight. The interventions included goal-setting, evidence-based education, operational planning, and incentive payments for non-physician health workers. A second survey to measure the final metabolic risk factors was performed after one year. The difference-in-difference method was used to evaluate the effectiveness of the intervention packages.

Results: The average age of participants in both surveys was 49 years, and the sex ratio did not change. In percentage of surveyed individuals with a college education was greater in non-intervention centers. The interventions had statistically significant effects only on decreasing the prevalence of overweight and obesity. The package with all the interventions except pay-for-performance decreased the odds of overweight and obesity to 0.57 ( $95 \% \mathrm{Cl}$ : $0.34,0.95)$.

Conclusion: Involving non-physician health workers and having action plans based on the health needs of the covered population, as well as holding training courses, and introducing new prevention and control strategies, can decrease obesity and overweight in the community. However, longer trials are needed to observe the effects on hypertension and hyperlipidemia.

Trial Registration: This trial was registered in the Iranian Registry of Clinical Trials (IRCT20081205001488N2) on 3 June 2018 (https://en.irct.ir/trial/774).

\section{Introduction}

Non-communicable diseases (NCDs) cause approximately $80 \%$ of deaths worldwide and $83 \%$ in Iran [1, 2]. Metabolic risk factors-e.g., hypertension, obesity and overweight (OB/OW), hypertriglyceridemia, high levels of low-density lipoprotein (LDL-C), low levels of high-density lipoprotein cholesterol (HDLC), and glucose intolerance [3] — are associated with a range of NCDs, especially cardiovascular diseases and cancers. Globally, 10.4 million deaths and 218 million disability-adjusted life years (DALYs) were attributable to metabolic risk factors in 2017[4]. According to the Global Burden of Disease 2019 report, $30.6 \%$ of all deaths in Iran were attributable to hypertension, $20.1 \%$ to high fasting plasma glucose, $18.8 \%$ to OB/OW, and $16.1 \%$ to hyperlipidemia. Also, $13.8 \%$ of all DALYs were attributable to hypertension, $12.9 \%$ to OB/OW, $11.5 \%$ to high fasting plasma glucose, and $7.8 \%$ to hyperlipidemia [5].

Given their remarkable public health risks, managing NCDs is essential. Considering the health care sector's limited budget in developing countries, costeffective interventions are needed to achieve the global goal of $25 \%$ relative risk reduction in premature deaths from NCDs by 2025 [6] and the Sustainable Development Goals (SDG) target of reducing premature death from NCDs by one-third by 2030 [7].

The burden on NCDs can be reduced if their metabolic risk factors are managed. The leading modifiable risk factor for cardiovascular disease is hypertension [8], which can be asymptomatic. Approximately 20\% [9] and sometimes up to 50\% [10] of cases are not known by patients. A systematic review showed that every $10 \mathrm{mmHg}$ reduction in blood pressure results in about $28 \%$ reduction in heart failure, $27 \%$ in stroke, $17 \%$ in coronary heart disease, and $13 \%$ in all-cause mortality rate. [11]. Also, patients with hyperlipidemia often do not show any symptoms until atherosclerosis eventually leads to a heart attack or stroke [12], while approximately $51 \%$ of the burden of heart disease and $12 \%$ of the burden of ischemic stroke are attributable to high cholesterol [13]. OB/OW can increase the risk of various types of cancer [14], coronary heart disease, type 2 diabetes, gallstones, and disability [15, 16]. It is estimated that a one-kilogram weight loss can reduce the risk of diabetes by about $16 \%$ [17]; also, a 5-10\% weight loss can reduce systolic and diastolic blood pressure levels by $5 \mathrm{mmHg}$ [18], decrease triglyceride by 25 to $40 \mathrm{mg} / \mathrm{dL}$ [19], and increase HDL by 5 mg/dL [20]. Hence, investing in NCDs management by improving identification, screening, and treatment of NCDs can significantly improve community public health status [21]. Essential interventions can be provided through primary health care (PHC) providers to enhance timely diagnosis and treatment. Various intervention methods have been utilized which focus on PHC providers to control NCDs [22, 23]. Nonetheless, a 2018 World Health Organization (WHO) report indicated that more than $50 \%$ of countries are likely to miss their 2030 NCDs targets $[24,25]$.

In line with Iran's Health Transformation Program, the country's Ministry of Health and Medical Education (MOHME) established a Non-Communicable Diseases Committee (NCDC) in 2015 to develop evidence-based policies and monitor their proper implementation to achieve the related SDG targets [26]. In 2016, the NCDC developed the IraPEN program, adapted from the WHO Package of Essential Noncommunicable Disease Interventions (WHO PEN) for PHC setting in low-resource areas [27]. Despite the nationwide scaling up of the PHC system under IraPEN, there have been challenges in the quality of implementation, stemming from insufficient knowledge and skills of care providers for building trust with clients (assurance dimension), failure to provide timely services, and lack of empathy with clients [28].

This study adopted a set of strategies to overcome the aforementioned implementation challenges. The first strategy was goal-setting by holding workshops to inform non-physician health workers (NPHWs) about NCDs metabolic risk factors' status of their covered populations and the country's goal to reduce the risks. The second strategy was evidence-based training of NPHWs by introducing innovative interventions and cost-effective implementation methods. The third strategy was setting an action plan for NPHWs and providing ongoing advice during the implementation phase, along with financial support for implementation. The fourth strategy was incentivizing NPHWs based on their performance in meeting a set of pre-determined goals. This study aimed to measure the most effective set of strategies in preventing and controlling NCDs metabolic risk factors (MetRFs). 


\section{Materials And Methods The Design of the Field Trial}

This study was part of a larger project. The entire protocol of the study has already been published [29]. Four districts in the country were selected for the field trial: three districts as intervention districts, and one as a non-intervention (control) district. The non-intervention district was Garmsar, 114 kilometers (km) southeast of Tehran (the country's capital city), with a covered population of 77,421, according to the country's 2016 census [30]. The intervention districts were Shahriar (46 km southwest of Tehran), Damghan (337 km northeast of Tehran), and Dashtestan (986 km south of Tehran), with a total 2016 population of 1,090,447 (Figure 1) [30].

Four urban and four rural community health centers (CHCs) were randomly selected in each district, for a total of 32 centers. CHCs inclusion criteria were described in detail in the published protocol [29]. The key inclusion criteria for a CHC were having at least two NPHWs with expressed willingness to participate in the study and to keep working at the $\mathrm{CHC}$ for at least two years. Physicians were not included in this trial, because the performance-based payment program for them is running in Iran [31].

In all selected $\mathrm{CHCs}$, baseline surveys of the 30- to 70-year-old individuals were conducted from June to September 2018 to determine the existing status of MetRFs. The surveys were structured based on the Persian version of the WHO stepwise approach to surveillance Questionnaire (STEPS) [32].

Subsequently, four different intervention packages were randomly assigned to the eight CHCs in each intervention district. One pair of urban and rural CHCs in each district received the first intervention package, another pair received the second intervention package, and so on (Table 1). After a 12-month period of intervention implementation, the second survey of NCDs MetRFs was conducted in all CHCs from September to November 2019 to evaluate the effectiveness of the intervention packages (Figure 2).

This study was planned for two years, and the third survey after 24 months of intervention was expected to be performed. However, it was terminated prematurely after 12 months of intervention due to the limitations imposed by the COVID-19 pandemic.

\section{Intervention Packages}

The basic intervention package (Package A) included only goal-setting seminars for NPHWs. During the seminars, short-term targets such as specific reduction levels in the prevalence of $\mathrm{OB} / \mathrm{OW}$ in the covered population and the country's national document to control and prevent NCDs and related risk factors were placed[33]. The targets were set based on the initial results of the baseline survey.

The second intervention package (Package B) had an extra element in addition to goal-setting for NPHWs: it included evidence-based education of NPHWs through a two-day training workshop. The research team held the workshops at each of the districts. During the workshop, the effect of similar interventions on the prevention and control of NCDs MetRFs was presented and discussed. The workshop training materials came from the World Bank's Disease Control Priorities, Volume 5, and the WHO PEN [22, 23].

In the third intervention package (Package C), operational planning for NPHWs was added to goal-setting and evidence-based education. The research team along with the NPHWs prepared an operational plan for each $\mathrm{CHC}$ based on the baseline survey's findings for the CHC's covered population. For example, if $\mathrm{OB} / \mathrm{OW}$ was the main MetRFs in the covered population, the plan emphasized actions that addressed OB/OW like encouraging regular daily walking sessions in the community with the participation of NPHWs. The team also allocated budgets for the designed operational plans and provided consultations to NPHWs during the plans' implementation.

The fourth intervention package (Package D) added performance-based financing to the previous three elements. NPHWs received performance-based payments every three months with no delay if they met the pre-determined goals. If they reached at least $62.50 \%$ of their goals, they received the maximum incentive payment, $10 \%$ of a typical NPHW's average monthly salary. An NPHW's average monthly salary in 2018 was approximately 25 million Rials or 232 USD at a $107,832 \mathrm{Rial} / \mathrm{USD}$ current exchange rate [34]. If they reached $50.00-62.49 \%$ of their goals, NPHWs received an incentive equivalent to $8 \%$ of a typical NPHW's average monthly salary, $6 \%$ if they achieved from $25.00-49.99 \%$ of their goals. There was no incentive payment if NPHWs reached less than $25.00 \%$ of their goals. The incentive amounts were determined after consulting with districts and provincial supervisors and a focus group's discussions with NPHWs. The assignment of the intervention packages is shown in Table 1.

Every two to four weeks, the implementation of interventions in the $\mathrm{CHCs}$ was monitored by the district and provincial supervisors. Similarly, the research team monitored the interventions every three months and collected related reports and documents. 
Table 1

Assignment of interventions to $\mathrm{CHCs}$ in each of the three treatment districts

\begin{tabular}{|c|c|c|c|c|c|}
\hline \multirow{2}{*}{$\begin{array}{l}\text { Intervention } \\
\text { Package }\end{array}$} & \multirow{2}{*}{$\begin{array}{l}\text { Intervention Groups: Selected } \\
\text { CHCs }\end{array}$} & \multicolumn{4}{|c|}{ Intervention: } \\
\hline & & $\begin{array}{l}\text { Goal- } \\
\text { Setting }\end{array}$ & $\begin{array}{l}\text { Evidence-Based } \\
\text { Education }\end{array}$ & $\begin{array}{l}\text { Operational } \\
\text { Planning }\end{array}$ & $\begin{array}{l}\text { Performance-Based } \\
\text { Financing }\end{array}$ \\
\hline A & 1 Rural, 1 Urban & Yes & No & No & No \\
\hline B & 1 Rural, 1 Urban & Yes & Yes & No & No \\
\hline C & 1 Rural, 1 Urban & Yes & Yes & Yes & No \\
\hline D & 1 Rural, 1 Urban & Yes & Yes & Yes & Yes \\
\hline
\end{tabular}

\section{Statistical analysis}

The objective of this study was to identify effective intervention packages by comparing the NCDs MetRFs before and after interventions within and between CHCs. NCDs MetRFs analyzed in this study were zero-one indicators of uncontrolled hypertension, hyperlipidemia, OB/OW. Supplementary analyses were performed to compare the mean systolic and diastolic blood pressure, total cholesterol, and BMI before and after the interventions.

Criteria for identifying hypertension were systolic blood pressure (SBP) of $140 \mathrm{mmHg}$ or higher, diastolic blood pressure (DBP) of $90 \mathrm{mmHg}$ or higher, a physician or a nurse's diagnosis, or taking medication to control hypertension over the last fourteen days [35]. Criteria for identifying Hypercholesterolemia included a total cholesterol level of $200 \mathrm{mg} / \mathrm{dL}$ or higher, a physician or a nurse's diagnosis, or taking medication to control high cholesterol over the last fourteen days [36]. Body mass index (BMI) between $25.00 \mathrm{~kg} / \mathrm{m}^{2}$ and $29.99 \mathrm{~kg} / \mathrm{m}^{2}$ was defined as overweight, and obese if greater than or equal to 30.00 $\mathrm{kg} / \mathrm{m}^{2}[37]$.

Prevalence and mean differences between the two surveys were calculated. Then, the difference-in-difference (DID) framework was used to identify the effect of the intervention packages. The following equation shows the linear specification of the DID design:

$$
Y_{i c t}=\alpha+\beta \text { Package }_{i c}+\gamma \text { Post }_{i t}+\rho\left(\text { Package }_{i c} \times \text { Post }_{i t}\right)+\theta C H C_{i t}+\delta X_{i c t}+\epsilon_{i c t}
$$

where $i$ indicates a surveyed individual, $c$ indicates the $\mathrm{CHC}$ through which the individual received PHC services, and $t$ indicates survey year. The dependent variable, $Y$, was a binary variable indicating one of the NCDs MetRFs or a continuous measure of NCDs MetRFs. The variable Package was a categorical variable containing $0,1,2,3$, and 4, representing no intervention CHCs, packages A, B, C, and D, respectively. The variable Post was set equal to 0 if individual $i$ participated in the baseline survey in 2018, or 1 if participated in the post-intervention survey in 2019. The variable $C H C$ contains values 1 through 32, capturing $\mathrm{CHC}$-level time-invariant effects. The variable $X$ is a vector of demographic and socioeconomic factors including age, sex, marital status, education level, job status, health insurance status, and homeownership status. The coefficient $\rho$ is the coefficient of interest.

Given the binary and continuous nature of the outcome variables in this study, logistic and linear models were used in fitting equation (1). Odds ratios and coefficients were calculated, representing the change in the dependent variable in association with changes in the explanatory variables of the equation. Standard errors were clustered at the $\mathrm{CHC}$ level to account for the possibility that the NCDs MetRFs may not be independently distributed within the population covered by each $\mathrm{CHC}$ [38]. Sampling weights were used in the regressions. The weights were the multiplication of two ratios. The first ratio was the share of sex-specific age groups (namely, 30-39, 40-49, 50-59, 60-70 years) in urban and rural areas in the country. The second ratio was the share of surveyed people of the same sex and age group in the individual's corresponding CHC, separately for urban and rural $\mathrm{CHCs}$. The analysis was conducted with and without adjusting for the set of socioeconomic factors, $X$, to assess omitted variable bias due to observables. The statistical package used for analyses was STATA 14.0 (STATA, Inc, College Station, Texas).

\section{Results}

A total of 2446 individuals, 30- to 70-year-old, participated in the two surveys: 1225 in the first, and 1221 in the second survey. The mean age of participants was 49.27 (SD of 0.33 ) and 49.38 (SD of 0.32) years in the first and second surveys, respectively. About equal number of men and women participated in the surveys. Women comprised $50.12 \%$ of the first survey and $50.37 \%$ of the second survey. The majority of the participants were illiterate or had primary school education: $43.48 \%$ and $42.45 \%$ in the first and second surveys, respectively. On the other hand, college-educated participants were in the minority: $10.76 \%$ of the first survey, and $11.25 \%$ of the second survey. Most of the participants were married ( $85.42 \%$ and 85.44 in first and second surveys), homeowners (83.85\% in the first, $85.09 \%$ in the second survey), and homemakers (42.29\% and $46.49 \%$ in the first and second surveys). Also, most of them had health insurance $(92.58 \%$ in first and $94.74 \%$ in the second survey) (Table 2 ).

The characteristics of participants across the study groups were largely similar. The most noticeable difference among the study groups was the low share of illiterate participants in the non-intervention group (25.83\% in the first and $23.66 \%$ in the second survey) compared to the intervention groups (between $36.73 \%$ and $55.45 \%$ ). Also, the percentage of homeowner participants in the intervention group that received Package D (70.68\% and $77.43 \%$ in the two 
surveys) was smaller than that in other groups (between $79.17 \%$ and $92.89 \%$ ). In addition, the rate of self-employment across the groups fluctuate between $14.48 \%$ and $40.57 \%$. Such differences highlight the importance of adjusting for socioeconomic characteristics in statistical analyses.

The crude difference in the prevalence of the studied NCDs MetRFs before and after the interventions was usually negative but rarely statistically significant (Table 3). The only statistically significant change was in hyperlipidemia. It occurred in CHCs that received the intervention Package B (goal-setting and evidence-based training). Its prevalence decreased from $47.22-37.23 \%$, a $9.99 \%$ decrease with a $95 \%$ confidence interval (Cl) of $0.87-19.11 \%$ decrease. This was the largest decrease in the prevalence of the NCDs MetRFs. The second-largest decrease belonged to OB/OW and occurred in $\mathrm{CHCs}$ that received the intervention Package $\mathrm{C}$ (goal-setting, evidence-based training, and operational planning). In these $\mathrm{CHCs}$, the prevalence of OB/OW decreased from $72.41-66.22 \%$, a $6.19 \%$ decrease (95\% $\mathrm{Cl}:-15.26 \%, 2.88 \%)$.

The before-after differences could have been influenced by the effect of time. If the effect of time on the studied outcomes was the same in the intervention and non-intervention CHCs, the DID design could identify the effects of the interventions independent of time. DID results, adjusted and unadjusted for socioeconomic characteristics, are presented in Table 4. The DID estimates generally showed a decrease in the odds of incidence of hypertension, hyperlipidemia, and $\mathrm{OB} / \mathrm{OW}$ in the intervention $\mathrm{CHCs}$ versus the non-intervention $\mathrm{CHCs}$. The odds of decrease, however, were statistically significant in only one case: the prevalence of $\mathrm{OB} / \mathrm{OW}$ in $\mathrm{CHCs}$ that received the intervention package $\mathrm{C}$ (goal-setting, evidence-based training, and operational planning). Specifically, the adjusted DID estimates showed that the odds of reporting OB/OW in CHCs receiving package $\mathrm{C}$ versus that in non-intervention $\mathrm{CHCs}$ decreased to $0.57(95 \% \mathrm{Cl}: 0.34,0.95)$. It is interesting to note that one of the most significant decreases in the NCDs MetRFs prevalence rates also occurred for the same package and risk factor (Table 3).

The results of similar analyses with non-dichotomous outcome variables for the studied NCDs MetRFs are presented in Table 5 and Table 6 . The crude comparison of the average levels of SBP, DBP, total cholesterol, and BMI do not show a consistent pattern of the effect of the intervention packages (Table 5). Although close to $95 \%$ statistically significant decreases in levels of the MetRFs were observed in some MetRFs (namely, in SBP, total cholesterol, and BMI with Package $C$ and in BMI with Package D), statistically significant increases were observed in some other MetRFs (namely, in DSB and SBP with Packages $B$ and $D$ and no intervention and in total cholesterol with no intervention). However, the main finding of the analyses with the dichotomous MetRFs outcome variables - that the odds of $\mathrm{OB} / \mathrm{OW}$ decreased with Package $\mathrm{C}$ - was not rejected by the Table 5 comparisons, as Package $\mathrm{C}$ was also associated with a reduction in the average BMI level. The average BMI in CHCs receiving Package C was $0.88 \mathrm{~kg} / \mathrm{m}^{2} \mathrm{less}$ than what it was in the baseline survey ( $95 \% \mathrm{Cl}$ for units of decrease: $\left.-0.30 \mathrm{~kg} / \mathrm{m}^{2}, 2.05 \mathrm{~kg} / \mathrm{m}^{2}\right)$.

When the comparisons of the NCDs MetRFs in levels were adjusted for individuals' socioeconomic characteristics and the common time trends in the outcome variables across CHCs were eliminated through a DID design, no statistically significant increase was seen. Still, some statistically significant decreases were preserved (Table 6). Specifically, there was an almost 95\% statistically significant decrease in SBP with intervention package C: SBP decreased by $7.88 \mathrm{mmHg}(95 \% \mathrm{Cl}$ for decrease: $-0.23 \mathrm{mmHg}, 15.98 \mathrm{mmHg})$ among the population covered by CHCs receiving Package $\mathrm{C}$ versus the nonintervention group. Another close to statistical significance results belonged to BMI level decrease with the intervention package $\mathrm{C}$ : BMI decreased by 1.26 $\mathrm{kg} / \mathrm{m}^{2}$ (95\% Cl for decrease: $-0.43 \mathrm{~kg} / \mathrm{m}^{2}, 2.95 \mathrm{~kg} / \mathrm{m}^{2}$ ) among the population covered by $\mathrm{CHCs}$ receiving Package $\mathrm{C}$ versus the non-intervention group. 
Table 2

Demographic and economic characteristics of participants (frequencies and percentages)

\begin{tabular}{|c|c|c|c|c|c|c|c|c|c|c|c|c|}
\hline \multirow{4}{*}{$\begin{array}{l}\text { Socioeconomic } \\
\text { Factors }\end{array}$} & \multirow{2}{*}{\multicolumn{2}{|c|}{$\begin{array}{l}\text { Total, } \\
\mathrm{n}=\mathbf{2 4 4 6}\end{array}$}} & \multicolumn{10}{|c|}{ Intervention Package } \\
\hline & & & \multicolumn{2}{|c|}{$\begin{array}{l}\text { Package } A \\
n=445\end{array}$} & \multicolumn{2}{|c|}{$\begin{array}{l}\text { Package } B \text {, } \\
n=463\end{array}$} & \multicolumn{2}{|c|}{$\begin{array}{l}\text { Package } C, \\
n=465\end{array}$} & \multicolumn{2}{|c|}{$\begin{array}{l}\text { Package } D \text {, } \\
n=450\end{array}$} & \multicolumn{2}{|l|}{$\begin{array}{l}\text { None, } \\
n=623\end{array}$} \\
\hline & $\begin{array}{l}\text { Survey } \\
1\end{array}$ & $\begin{array}{l}\text { Survey } \\
2\end{array}$ & $\begin{array}{l}\text { Survey } \\
1\end{array}$ & $\begin{array}{l}\text { Survey } \\
2\end{array}$ & $\begin{array}{l}\text { Survey } \\
1\end{array}$ & $\begin{array}{l}\text { Survey } \\
2\end{array}$ & $\begin{array}{l}\text { Survey } \\
1\end{array}$ & $\begin{array}{l}\text { Survey } \\
2\end{array}$ & $\begin{array}{l}\text { Survey } \\
1\end{array}$ & $\begin{array}{l}\text { Survey } \\
2\end{array}$ & $\begin{array}{l}\text { Survey } \\
1\end{array}$ & $\begin{array}{l}\text { Survey } \\
2\end{array}$ \\
\hline & $n=1225$ & $n=1221$ & $n=225$ & $n=220$ & $n=232$ & $\mathrm{n}=\mathbf{2 3 1}$ & $n=239$ & $n=226$ & $n=224$ & $\mathrm{n}=\mathbf{2 2 6}$ & $n=305$ & $n=318$ \\
\hline Mean Age & 49.27 & 49.38 & 49.52 & 49.58 & 49.31 & 49.28 & 49.89 & 49.13 & 48.89 & 49.11 & 48.85 & 49.67 \\
\hline $\begin{array}{l}\text { (Standard } \\
\text { Deviation) }\end{array}$ & $(0.33)$ & $(0.32)$ & & $(0.74)$ & $(0.73)$ & $(0.76)$ & $(0.73)$ & $(0.74)$ & $(0.78)$ & $(0.73)$ & $(0.65)$ & $(0.63)$ \\
\hline \multicolumn{13}{|l|}{ Sex: } \\
\hline Male & 611 & 606 & 112 & 107 & 117 & 117 & 113 & 107 & 110 & 117 & 159 & 158 \\
\hline (\%) & $(49.88)$ & $(49.63)$ & $(49.78)$ & $(48.64)$ & $(50.43)$ & $(50.65)$ & $(47.28)$ & $(47.35)$ & $(49.11)$ & $(51.77)$ & $(52.13)$ & $(49.69)$ \\
\hline Female & 614 & 615 & 113 & 113 & 115 & 114 & 126 & 119 & 114 & 109 & 146 & 160 \\
\hline (\%) & $(50.12)$ & $(50.37)$ & $(50.22)$ & $(51.36)$ & $(49.57)$ & $(49.35)$ & $(52.72)$ & $(52.65)$ & $(50.89)$ & $(48.23)$ & $(47.87)$ & $(50.31)$ \\
\hline \multicolumn{13}{|l|}{ Education: } \\
\hline Illiterate/Primary & 497 & 517 & 105 & 122 & 109 & 116 & 117 & 121 & 88 & 83 & 78 & 75 \\
\hline (\%) & $(43.48)$ & $(42.45)$ & $(50.00)$ & $(55.45)$ & $(49.10)$ & $(50.43)$ & $(52.47)$ & (53.78) & $(47.31)$ & $(36.73)$ & $(25.83)$ & $(23.66)$ \\
\hline Secondary School & 158 & 196 & 19 & 35 & 39 & 39 & 20 & 30 & 27 & 44 & 53 & 48 \\
\hline (\%) & $(13.82)$ & (16.09) & $(9.05)$ & (15.91) & (17.57) & $(16.96)$ & $(8.97)$ & (13.33) & $(14.52)$ & (19.47) & (17.55) & (15.14) \\
\hline High School & 365 & 368 & 65 & 43 & 58 & 64 & 68 & 52 & 45 & 70 & 129 & 139 \\
\hline (\%) & (31.93) & $(30.21)$ & (30.95) & (19.55) & $(26.13)$ & $(27.83)$ & $(30.49)$ & $(23.11)$ & $(24.19)$ & $(30.97)$ & $(42.72)$ & $(43.85)$ \\
\hline Some College & 123 & 137 & 21 & 2 & 16 & 11 & 18 & 22 & 26 & 29 & 42 & 55 \\
\hline (\%) & $(10.76)$ & $(11.25)$ & $(10.00)$ & (9.09) & $(7.21)$ & $(4.78)$ & $(8.07)$ & (9.78) & (13.98) & (12.83) & (13.91) & (17.35) \\
\hline \multicolumn{13}{|l|}{ Marital Status: } \\
\hline Never Married & 82 & 84 & 12 & 7 & 9 & 13 & 18 & 12 & 19 & 22 & 24 & 30 \\
\hline (\%) & $(7.03)$ & $(6.91)$ & $(5.74)$ & $(3.20)$ & $(4.07)$ & $(5.68)$ & $(8.11)$ & $(5.36)$ & $(8.96)$ & $(9.73)$ & (7.95) & $(9.43)$ \\
\hline Married & 996 & 1039 & 187 & 198 & 190 & 194 & 187 & 198 & 176 & 185 & 256 & 264 \\
\hline (\%) & $(85.42)$ & $(85.44)$ & $(89.47)$ & $(90.41)$ & $(85.97)$ & $(84.72)$ & $(84.23)$ & (88.39) & $(83.02)$ & (81.86) & $(84.77)$ & $(83.02)$ \\
\hline Divorced/Widowed & 88 & 93 & 10 & 14 & 22 & 22 & 17 & 14 & 17 & 19 & 22 & 24 \\
\hline (\%) & $(7.55)$ & (7.65) & $(4.78)$ & (6.39) & (9.95) & $(9.61)$ & $(7.66)$ & $(6.25)$ & $(8.02)$ & $(8.41)$ & $(7.28)$ & (7.55) \\
\hline \multicolumn{13}{|l|}{ Job: } \\
\hline $\begin{array}{l}\text { Public Wage and } \\
\text { Salay }\end{array}$ & 101 & 75 & 13 & 8 & 18 & 14 & 16 & 15 & 20 & 13 & 34 & 25 \\
\hline (\%) & $(8.70)$ & $(6.19)$ & $(6.25)$ & $(3.64)$ & $(8.11)$ & $(6.09)$ & $(7.24)$ & $(6.82)$ & $(9.43)$ & $(5.83)$ & $(11.41)$ & $(7.86)$ \\
\hline Private Wage and & 104 & 92 & 21 & 31 & 21 & 15 & 28 & 21 & 12 & 18 & 22 & 7 \\
\hline (\%) & $(8.96)$ & $(7.60)$ & $(10.10)$ & (14.09) & $(9.46)$ & $(6.52)$ & $(12.67)$ & $(9.55)$ & $(5.66)$ & $(8.07)$ & (7.38) & $(2.20)$ \\
\hline Self-Employed & 316 & 292 & 53 & 46 & 54 & 56 & 32 & 49 & 86 & 58 & 91 & 83 \\
\hline (\%) & $(27.22)$ & $(24.11)$ & $(25.48)$ & $(20.91)$ & $(24.32)$ & $(24.35)$ & $(14.48)$ & $(22.27)$ & $(40.57)$ & $(26.01)$ & $(30.54)$ & $(26.10)$ \\
\hline Homemaker & 491 & 563 & 89 & 103 & 98 & 110 & 110 & 105 & 73 & 102 & 121 & 143 \\
\hline (\%) & $(42.29)$ & $(46.49)$ & $(42.79)$ & $(46.82)$ & $(44.14)$ & $(47.83)$ & (49.77) & $(47.73)$ & (34.43) & $(45.74)$ & $(40.60)$ & (44.97) \\
\hline Retired & 91 & 132 & 20 & 24 & 19 & 24 & 22 & 19 & 12 & 25 & 18 & 40 \\
\hline (\%) & (7.84) & (10.90) & (9.62) & (10.91) & (8.56) & (10.43) & (9.95) & (8.64) & $(5.66)$ & (11.21) & $(6.04)$ & (12.58) \\
\hline
\end{tabular}




\begin{tabular}{|c|c|c|c|c|c|c|c|c|c|c|c|c|}
\hline \multirow{4}{*}{$\begin{array}{l}\text { Socioeconomic } \\
\text { Factors }\end{array}$} & \multirow{2}{*}{\multicolumn{2}{|c|}{$\begin{array}{l}\text { Total, } \\
\mathrm{n}=\mathbf{2 4 4 6}\end{array}$}} & \multicolumn{10}{|c|}{ Intervention Package } \\
\hline & & & \multicolumn{2}{|c|}{$\begin{array}{l}\text { Package } A \\
n=445\end{array}$} & \multicolumn{2}{|c|}{$\begin{array}{l}\text { Package } B \text {, } \\
n=463\end{array}$} & \multicolumn{2}{|c|}{$\begin{array}{l}\text { Package C, } \\
n=465\end{array}$} & \multicolumn{2}{|c|}{$\begin{array}{l}\text { Package } D, \\
n=450\end{array}$} & \multicolumn{2}{|l|}{$\begin{array}{l}\text { None, } \\
n=623\end{array}$} \\
\hline & $\begin{array}{l}\text { Survey } \\
1\end{array}$ & $\begin{array}{l}\text { Survey } \\
2\end{array}$ & $\begin{array}{l}\text { Survey } \\
1\end{array}$ & $\begin{array}{l}\text { Survey } \\
2\end{array}$ & $\begin{array}{l}\text { Survey } \\
1\end{array}$ & $\begin{array}{l}\text { Survey } \\
2\end{array}$ & $\begin{array}{l}\text { Survey } \\
1\end{array}$ & $\begin{array}{l}\text { Survey } \\
2\end{array}$ & $\begin{array}{l}\text { Survey } \\
1\end{array}$ & $\begin{array}{l}\text { Survey } \\
2\end{array}$ & $\begin{array}{l}\text { Survey } \\
1\end{array}$ & $\begin{array}{l}\text { Survey } \\
2\end{array}$ \\
\hline & $n=1225$ & $n=1221$ & $n=225$ & $n=220$ & $n=232$ & $\mathrm{n}=\mathbf{2 3 1}$ & $\mathrm{n}=\mathbf{2 3 9}$ & $n=226$ & $n=224$ & $n=226$ & $n=305$ & $n=318$ \\
\hline Unemployed & 58 & 57 & 12 & 8 & 12 & 11 & 13 & 11 & 9 & 7 & 12 & 20 \\
\hline (\%) & $(5.00)$ & $(4.71)$ & $(5.77)$ & $(3.64)$ & $(5.41)$ & $(4.78)$ & $(5.88)$ & $(5.00)$ & $(4.25)$ & $(3.14)$ & $(4.03)$ & $(6.29)$ \\
\hline \multicolumn{13}{|l|}{ Health Insurance: } \\
\hline Insured & 1035 & 1152 & 203 & 209 & 209 & 205 & 171 & 210 & 164 & 215 & 288 & 313 \\
\hline (\%) & $(92.58)$ & $(94.74)$ & $(96.21)$ & (95.43) & (94.57) & $(90.31)$ & $(96.07)$ & $(92.92)$ & $(78.85)$ & (95.13) & $(96.00)$ & $(98.43)$ \\
\hline Uninsured & 83 & 64 & 8 & 10 & 12 & 22 & 7 & 16 & 44 & 11 & 12 & 5 \\
\hline (\%) & $(7.42)$ & $(5.26)$ & $(3.79)$ & $(4.57)$ & $(5.43)$ & $(9.69)$ & $(3.93)$ & $(7.08)$ & $(21.15)$ & $(4.87)$ & $(4.00)$ & $(1.57)$ \\
\hline \multicolumn{13}{|l|}{ Homeownership: } \\
\hline Yes & 898 & 1027 & 183 & 171 & 170 & 209 & 164 & 192 & 135 & 175 & 246 & 280 \\
\hline (\%) & (83.85) & (85.09) & $(87.56)$ & (79.17) & (86.29) & (92.89) & $(92.66)$ & $(86.10)$ & $(70.68)$ & (77.43) & (82.83) & (88.33) \\
\hline No & 173 & 180 & 26 & 45 & 27 & 16 & 13 & 31 & 56 & 51 & 51 & 37 \\
\hline (\%) & $(16.15)$ & $(14.91)$ & $(12.44)$ & $(20.83)$ & (13.71) & $(7.11)$ & $(7.34)$ & $(13.90)$ & $(29.32)$ & $(22.57)$ & $(17.17)$ & (11.67) \\
\hline
\end{tabular}

Table 3

The difference in NCDs metabolic risk factors' prevalence between two surveys

\begin{tabular}{|c|c|c|c|c|}
\hline NCDs & Intervention Package & First & Second & Difference (\%) \\
\hline Risk & & Survey & Survey & (95\% Confidence Interval) \\
\hline Factors & & $(\%)$ & $(\%)$ & \\
\hline \multirow[t]{5}{*}{ Hypertension } & $A$ & 38.38 & 36.36 & $-2.02(-11.16,7.11)$ \\
\hline & $\mathrm{B}$ & 47.84 & 43.72 & $-4.12(-13.43,5.19)$ \\
\hline & $\mathrm{C}$ & 36.58 & 38.05 & $1.47(-7.67,10.61)$ \\
\hline & $\mathrm{D}$ & 37.50 & 34.07 & $-3.43(-12.45,5.59)$ \\
\hline & None & 31.25 & 35.01 & $3.76(-3.63,11.16)$ \\
\hline \multirow[t]{5}{*}{ Hyperlipidemia } & $A$ & 22.91 & 31.02 & $8.11(-0.46,16.67)$ \\
\hline & B & 47.22 & 37.23 & $-9.99(-19.11,-0.87)$ \\
\hline & $\mathrm{C}$ & 33.17 & 38.05 & $4.88(-4.12,13.88)$ \\
\hline & $\mathrm{D}$ & 30.39 & 29.77 & $-0.62(-9.31,8.07)$ \\
\hline & None & 30.87 & 26.18 & $-4.69(-11.82,2.45)$ \\
\hline \multirow[t]{5}{*}{ Obesity \& Overweight } & A & 70.44 & 73.61 & $3.17(-5.43,11.77)$ \\
\hline & $\mathrm{B}$ & 71.76 & 67.39 & $-4.37(-12.89,4.16)$ \\
\hline & $\mathrm{C}$ & 72.41 & 66.22 & $-6.19(-15.26,2.88)$ \\
\hline & D & 72.54 & 69.91 & $-2.63(-11.19,5.92)$ \\
\hline & None & 69.39 & 71.47 & $2.08(-5.18,9.35)$ \\
\hline
\end{tabular}


Table 4

Estimated effects of the intervention packages on the incidence of NCDs metabolic risk factors

\begin{tabular}{|c|c|c|c|c|c|}
\hline \multirow{3}{*}{$\begin{array}{l}\text { NCDs } \\
\text { Risk } \\
\text { Factor }\end{array}$} & \multirow{3}{*}{$\begin{array}{l}\text { Intervention } \\
\text { Package }\end{array}$} & \multicolumn{2}{|l|}{ Unadjusted } & \multicolumn{2}{|c|}{ Adjusted for Socioeconomic Factors } \\
\hline & & Odds Ratio & p-value & Odds Ratio & p-value \\
\hline & & $(95 \% \mathrm{Cl})$ & & $(95 \% \mathrm{Cl})$ & \\
\hline \multirow[t]{5}{*}{ Hypertension } & A & $0.66(0.41,1.07)$ & 0.095 & $0.69(0.39,1.22)$ & 0.201 \\
\hline & B & $0.66(0.29,1.49)$ & 0.322 & $0.72(0.34,1.52)$ & 0.386 \\
\hline & C & $1.07(0.57,2.04)$ & 0.825 & $0.88(0.41,1.91)$ & 0.751 \\
\hline & D & $0.76(0.40,1.44)$ & 0.399 & $0.64(0.29,1.41)$ & 0.273 \\
\hline & None & Reference Group & & & \\
\hline \multirow[t]{5}{*}{ Hyperlipidemia } & A & $1.50(0.62,3.65)$ & 0.373 & $1.78(0.66,4.48)$ & 0.257 \\
\hline & B & $0.77(0.31,1.95)$ & 0.584 & $0.95(0.34,2.68)$ & 0.926 \\
\hline & C & $1.71(0.81,3.59)$ & 0.159 & $1.65(0.70,3.89)$ & 0.252 \\
\hline & D & $1.18(0.50,2.76)$ & 0.710 & $1.39(0.45,4.30)$ & 0.565 \\
\hline & None & Reference Group & & & \\
\hline \multirow{5}{*}{$\begin{array}{l}\text { Obesity } \\
\& \\
\text { Overweight }\end{array}$} & A & $0.96(0.67,1.35)$ & 0.801 & $0.97(0.67,1.40)$ & 0.855 \\
\hline & B & $0.76(0.37,1.56)$ & 0.449 & $0.68(0.31,1.50)$ & 0.339 \\
\hline & C & $0.72(0.45,1.14)$ & 0.158 & $0.57(0.34,0.95)$ & 0.030 \\
\hline & D & $0.83(0.38,1.79)$ & 0.629 & $0.72(0.33,1.55)$ & 0.404 \\
\hline & None & Reference Group & & & \\
\hline
\end{tabular}


Table 5

The mean difference in NCDs metabolic risk factors' levels between two surveys

\begin{tabular}{|c|c|c|c|c|c|c|}
\hline \multirow{3}{*}{$\begin{array}{l}\text { NCDs } \\
\text { Risk } \\
\text { Factors }\end{array}$} & \multirow{3}{*}{$\begin{array}{l}\text { Intervention } \\
\text { Package }\end{array}$} & \multirow{2}{*}{\multicolumn{2}{|c|}{$\begin{array}{l}\text { First } \\
\text { Survey }(n=1,114)\end{array}$}} & \multirow{2}{*}{\multicolumn{2}{|c|}{$\begin{array}{l}\text { Second } \\
\text { Survey }(n=1,219)\end{array}$}} & \multirow{3}{*}{$\begin{array}{l}\text { Mean Difference } \\
\text { (95\% Confidence Interval) }\end{array}$} \\
\hline & & & & & & \\
\hline & & Mean & SD & Mean & SD & \\
\hline \multirow{5}{*}{$\begin{array}{l}\text { Systolic } \\
\text { Blood } \\
\text { Pressure }\end{array}$} & $A$ & 121.77 & 18.94 & 123.02 & 16.90 & $1.25(-2.15,4.64)$ \\
\hline & $B$ & 120.89 & 18.13 & 127.64 & 20.22 & $6.75(3.04,10.46)$ \\
\hline & $\mathrm{C}$ & 123.98 & 17.96 & 120.72 & 17.68 & $-3.26(-6.65,0.12)$ \\
\hline & $\mathrm{D}$ & 118.11 & 16.35 & 122.93 & 16.99 & $4.82(1.66,7.98)$ \\
\hline & None & 118.14 & 15.12 & 122.72 & 15.02 & $4.58(2.20,6.96)$ \\
\hline \multirow{5}{*}{$\begin{array}{l}\text { Diastolic } \\
\text { Blood } \\
\text { Pressure }\end{array}$} & $A$ & 81.32 & 10.77 & 80.77 & 10.05 & $-0.54(-2.52,1.43)$ \\
\hline & B & 79.66 & 10.64 & 82.84 & 12.02 & $3.18(0.99,5.38)$ \\
\hline & $\mathrm{C}$ & 80.05 & 10.16 & 80.74 & 10.76 & $0.68(-1.31,2.68)$ \\
\hline & $\mathrm{D}$ & 78.41 & 10.82 & 80.31 & 10.02 & $1.90(-0.07,3.87)$ \\
\hline & None & 76.04 & 10.33 & 78.66 & 9.44 & $2.63(1.07,4.19)$ \\
\hline \multirow{5}{*}{$\begin{array}{l}\text { Total } \\
\text { Cholesterol }\end{array}$} & $A$ & 171.50 & 32.71 & 175.48 & 40.15 & $3.98(-4.88,12.85)$ \\
\hline & B & 180.66 & 36.72 & 176.52 & 38.28 & $-4.14(-12.59,4.31)$ \\
\hline & C & 178.01 & 35.96 & 171.09 & 34.46 & $-6.92(-14.47,0.63)$ \\
\hline & $\mathrm{D}$ & 174.62 & 35.13 & 177.16 & 39.87 & $2.54(-6.07,11.14)$ \\
\hline & None & 168.83 & 36.34 & 173.70 & 34.84 & $4.86(-1.76,11.49)$ \\
\hline \multirow[t]{5}{*}{ BMI } & $A$ & 27.81 & 5.24 & 28.19 & 5.19 & $0.38(-0.62,1.38)$ \\
\hline & B & 28.15 & 5.84 & 28.03 & 6.15 & $-0.12(-1.24,1.00)$ \\
\hline & C & 28.42 & 6.74 & 27.54 & 5.17 & $-0.88(-2.05,0.30)$ \\
\hline & $\mathrm{D}$ & 28.04 & 4.75 & 27.56 & 4.73 & $-0.48(-1.38,0.42)$ \\
\hline & None & 27.80 & 5.89 & 27.66 & 4.84 & $-0.14(-1.00,0.72)$ \\
\hline
\end{tabular}


Table 6

Estimated effects of intervention packages on the levels of NCDs metabolic risk factors

\begin{tabular}{|c|c|c|c|c|c|}
\hline \multirow[t]{2}{*}{ NCDs Risk factors } & \multirow[t]{2}{*}{ Intervention Package } & \multicolumn{2}{|l|}{ Unadjusted } & \multicolumn{2}{|c|}{ Adjusted for Socioeconomic Factors } \\
\hline & & $\begin{array}{l}\text { The Effect, } \beta \text {, with } \\
\text { (95\% Confidence interval) }\end{array}$ & p-value & $\begin{array}{l}\text { The Effect, } \beta \text {, with } \\
\text { (95\% Confidence interval) }\end{array}$ & p-value \\
\hline \multirow{5}{*}{$\begin{array}{l}\text { Systolic } \\
\text { Blood Pressure }\end{array}$} & A & $-2.60(-9.42,4.23)$ & 0.443 & $-3.03(-10.42,4.35)$ & 0.408 \\
\hline & B & $2.75(-4.51,10.00)$ & 0.446 & $1.45(-6.28,9.18)$ & 0.705 \\
\hline & C & $-5.77(-13.15,1.60)$ & 0.120 & $-7.88(-15.98,0.23)$ & 0.057 \\
\hline & $\mathrm{D}$ & $1.40(-7.18,9.97)$ & 0.742 & $-0.77(-8.91,7.37)$ & 0.848 \\
\hline & None & Reference Group & & & \\
\hline \multirow{5}{*}{$\begin{array}{l}\text { Diastolic } \\
\text { Blood Pressure }\end{array}$} & A & $-3.46(-8.01,1.09)$ & 0.131 & $-2.61(-7.74,2.51)$ & 0.307 \\
\hline & B & $0.27(-4.75,5.30)$ & 0.912 & $-0.35(-5.69,4.99)$ & 0.893 \\
\hline & C & $-1.85(-8.12,4.42)$ & 0.552 & $-3.61(-9.30,2.08)$ & 0.205 \\
\hline & $\mathrm{D}$ & $-1.35(-9.19,6.49)$ & 0.729 & $-2.63(-9.01,3.75)$ & 0.407 \\
\hline & None & Reference Group & & & \\
\hline \multirow[t]{5}{*}{ Total Cholesterol } & A & $-2.85(-18.53,12.82)$ & 0.713 & $-1.59(-16.70,13.53)$ & 0.832 \\
\hline & B & $-10.41(-26.78,5.96)$ & 0.204 & $-9.31(-26.05,7.43)$ & 0.265 \\
\hline & C & $-8.33(-23.66,7.00)$ & 0.276 & $-9.54(-27.49,8.41)$ & 0.287 \\
\hline & $\mathrm{D}$ & $-4.59(-15.29,6.10)$ & 0.388 & $-4.62(-16.44,7.20)$ & 0.432 \\
\hline & None & Reference Group & & & \\
\hline \multirow[t]{5}{*}{ BMI } & A & $0.58(-0.95,2.12)$ & 0.445 & $0.63(-0.91,2.17)$ & 0.408 \\
\hline & B & $0.49(-1.30,2.29)$ & 0.580 & $0.57(-1.34,2.49)$ & 0.546 \\
\hline & C & $-0.65(-2.41,1.12)$ & 0.460 & $-1.26(-2.95,0.43)$ & 0.139 \\
\hline & $\mathrm{D}$ & $-0.25(-1.96,1.46)$ & 0.769 & $-0.55(-2.17,1.06)$ & 0.491 \\
\hline & None & Reference Group & & & \\
\hline
\end{tabular}

\section{Discussion}

\section{An Overview}

One-third of Iranian adults suffer from at least one of the NCDs MetRFs analyzed in this study [39]. Hence, it is essential to manage these MetRFs. We examined the effects of four low-cost intervention packages on the NCDs MetRFs by conducting a field trial. We involved NPHWs to implement the interventions in a randomly selected set of CHCs in four districts. The basic package included setting goals for NPHWs to control NCD MetRFs in their CHCs. Other packages had additive components of evidence-based training, operational planning, and performance-based financing for NPHWs. Improvements were observed in $\mathrm{OB} / \mathrm{OW}$, and the most effective intervention package was Package $\mathrm{C}$ that included all interventions but performance-based financing. Neither of the packages had a statistically significant improvement effect on the prevalence of uncontrolled hypertension, although the effect of Package $\mathrm{C}$ on SBP level approached statistical significance. Also, no improvement effect of the intervention packages on hyperlipidemia and total cholesterol level was observed.

\section{Assessing BMI-Related Results}

This study's estimated improvements in BMI-related outcomes (namely, the incidence of OB/OW and the level of BMI) can be attributed to exercise and healthy diet training sessions organized by NPHWs in the studied communities. In communities without adequate facilities for physical activity, emphasis was placed on proper diet and counseling sessions. Previous research has shown that NPHWs' availability and proper communication with their clients are effective in behavioral changes in the population [40,41]. Another important factor in the effectiveness of community-based behavioral interventions in reducing $\mathrm{OB} / \mathrm{OW}$ is the duration of interventions. This analysis measured signs of effectiveness after one year of intervention. A review study of 6 articles reported a significant reduction in $\mathrm{OB} / \mathrm{OW}$ after an average of 10 months of population-based lifestyle interventions [42]. In another review of 21 studies, significant $\mathrm{OB} / \mathrm{OW}$ reductions of population-based lifestyle interventions were reported over 6 to 24 months [43]. In addition, a quasi-experimental study in Malaysia showed that community-based lifestyle interventions for 6 months had no effect on weight loss and obesity, but significant effects were observed after 12 months [44].

\section{Assessing Blood Pressure-Related Results}


No significant effect of the intervention packages on uncontrolled hypertension was measured in this study. However, a decrease in SBP levels was detected with Package $\mathrm{C}$. The effects are barely statistically significant at the $95 \%$ level. The limited effect of the interventions on the blood pressure level can be explained by NPHW' lack of authority to prescribe blood pressure medicine drugs and not receiving adequate supervision from physicians. Community-based interventions in Colombia and Malaysia showed that behavioral and therapeutic interventions supervised by local physicians were effective in improving blood pressure within 12 months [45]. Also, 12-month lifestyle consultations by NPHWs supervised by physicians led to SBP reduction in China [46]. Studies in Tunisia and Pakistan showed that implementing healthy lifestyle interventions for 2 to 3 years via CHCs and effective uses of local resources and networks decreased the SBP in the community [47, 48].

\title{
Assessing Cholesterol-Related Results
}

No significant effect of the studied interventions was measured on reducing total cholesterol and the incidence of hyperlipidemia. This result may also pertain to the lack of medication interventions by NPHWs and no physician supervision. In contrast to this study, the effectiveness of behavioral lifestyle interventions was documented when accompanied by therapeutic interventions $[49,50]$ and supervised by physicians [51, 52]. Another reason for not observing an effect on cholesterol-related outcomes may be the short one-year period of the interventions. Longer-term interventions could effectively lower total cholesterol [53-58]. For example, North Carolina Project [57] and Coalfields Healthy Heartbeat [58] showed effectiveness in lowering total cholesterol levels after 5 and 6 years, respectively.

\section{Features of Successful Community-Based Interventions}

The success of community-based interventions in decreasing NCDs MetRFs largely depends on the duration of interventions[59-62]. Duration is important because changes in NCDs MetRFs usually follow a specific sequence (e.g., hypertension follows OB/OW) [63-68]. Another critical determining factor is the extent of cross-sectoral and intra-sectoral coordination $[69,70]$. Using and coordinating various community resources (e.g., health care facilities other than CHCs, schools' networks, religious institutions, city and village councils, and non-governmental organizations) can advance messaging and incentivize public health improvements. Also, as NPHWs are not authorized to prescribe drugs, coordination with and supervision of physicians are essential when medication interventions are needed. In the Iranian health system, NPHWs are authorized to educate and encourage people for lifestyle modifications and follow up on physicians' prescription of medications [71]. Thus, their contributions to local health policies and the planning of health interventions are mainly indirect. However, the results of this and other studies showed that managing risk factors through NPHWs can result in significant improvements if combined with lifestyle and treatment interventions [72-74].

\section{Elements of Community-Based Interventions}

This research showed that a low-cost, pragmatic intervention that includes evidence-based training and innovative action plans could reduce OB/OW in the short term. Other studies have shown that holding training courses for health workers along with having operational plans with goals in the short, medium, and long term can have a significant impact on improving NCDs MetRFs[58, 75-77]. On the other hand, performance-based payment can create an infrastructure to improve performance. A potentially important factor in the ineffectiveness of incentive payments in this study was the insignificant amount of incentive payments: the maximum incentive payment was only $10 \%$ of a typical NPHW's average monthly salary, about 23 USD, every three months. Other studies have shown that better results were achieved with higher incentive payments [78-80].

\section{Conclusion}

Having action plans based on the health needs of the covered population and involving NPHWs in the plans, as well as holding retraining courses and introducing new strategies in the prevention and control of NCDs MetRFs are effective steps in controlling OB/OW in the community. This study was shortened because of the emergence of the COVID-19 pandemic. Improvements in other NCDs MetRFs might have been measured had the interventions been implemented for more than one year.

\author{
Abbreviations \\ NCDs \\ Noncommunicable diseases \\ SDGs \\ Sustainable Development Goals \\ MetRFs \\ Metabolic Risk Factors \\ WHO \\ World Health Organization \\ IraPEN \\ Iranian Package of Essential Noncommunicable diseases \\ NPHWs \\ Non-Physician community Health Workers \\ CHCs \\ Community Health Centers \\ STEPS \\ Stepwise approach to Surveillance
}


COVID-19

Coronavirus Disease of 2019

MOHME

Ministry of Health \& Medical Education

MET

Metabolic Equivalent of Task

DID

Difference-In-Difference

RCT

Randomized Controlled Trial.

\section{Declarations}

\section{Ethics approval and consent to participate}

This study has been approved by the national committee on ethics in medical research (code: IR.NIMAD.REC.1396.084) as well as our institutional review board (code: IR.IUMS.REC.1395.1057613). Written informed consent will be obtained from study participants.

\section{Consent for publication}

Not applicable.

\section{Availability of data and materials}

The datasets generated and/or analyzed during the current study are not publicly available as publications are planned but are available from the corresponding author on reasonable request.

\section{Competing interests}

The authors declare that they have no competing interests.

\section{Funding}

Research reported in this publication was supported by Elite Researcher Grant Committee under award number 958058 from the National Institutes for Medical Research Development (NIMAD), Tehran, Iran.

\section{Authors' contributions}

The study was designed by MML, MN, ATB, MAA, and SMK. MML, ATB, FMH, EB, and MAA were involved in the implementation and execution phase. Statistical Analysis was performed by MML, MAA, SMK and LJ. The whole project was supervised by MML, ATB and FMH. All authors were involved in drafting or critical review of the manuscript. All authors read and approved the submitted version.

\section{Acknowledgements}

The authors would like to thank the vice-chancellors of Public Health at Iran University of Medical Sciences (Tehran, Iran), Semnan University of Medical Sciences (Semnan, Iran), and Bushehr University of Medical Sciences (Bushehr, Iran) and the involved healthcare workers for their contribution to this project.

\section{References}

1. Global regional, and national comparative risk assessment of 79 behavioural, environmental and occupational, and metabolic risks or clusters of risks, 1990-2015: a systematic analysis for the Global Burden of Disease Study 2015. Lancet (London, England). 2016;388(10053):1659-724.

2. Global burden of 87 risk factors in 204 countries and territories, 1990-2019: a systematic analysis for the Global Burden of Disease Study 2019. Lancet (London, England). 2020;396(10258):1223-49.

3. Alberti KG, Eckel RH, Grundy SM, Zimmet PZ, Cleeman JI, Donato KA, et al. Harmonizing the metabolic syndrome: a joint interim statement of the International Diabetes Federation Task Force on Epidemiology and Prevention; National Heart, Lung, and Blood Institute; American Heart Association; World Heart Federation; International Atherosclerosis Society; and International Association for the Study of Obesity. Circulation. 2009;120(16):1640-5. 
4. Roth GA, Abate D, Abate KH, Abay SM, Abbafati C, Abbasi N, et al. Global, regional, and national age-sex-specific mortality for 282 causes of death in 195 countries and territories, 1980-2017: a systematic analysis for the Global Burden of Disease Study 2017. Lancet (London, England). 2018;392(10159):1736-88.

5. GBD. Results [database on the Internet]. Institute for Health Metrics and Evaluation (IHME)2020 [Available from: http://ghdx.healthdata.org/gbdresultstool.

6. Beaglehole R, Bonita R, Ezzati M, Alleyne G, Dain K, Kishore SP, et al. NCD Countdown 2025: accountability for the $25 \times 25$ NCD mortality reduction target. Lancet. 2014;384(9938):105-7.

7. Countdown N. NCD Countdown 2030: pathways to achieving Sustainable Development Goal target 3.4. Lancet (London, England). 2020.

8. Naghavi M, Abajobir A, Cristiana A, Abbas K, Abd-Allah F, Abera S, et al. Global, regional, and national age-sex specifc mortality for 264 causes of death, 1980-2016: A systematic analysis for the Global Burden of Disease Study 2016. Lancet (London, England). 2017;390:1151-210.

9. Roger VL, Go AS, Lloyd-Jones DM, Benjamin EJ, Berry JD, Borden WB, et al. Heart disease and stroke statistics-2012 update: a report from the American Heart Association. Circulation. 2012;125(1):e2-220.

10. Wang Z, Chen Z, Zhang L, Wang X, Hao G, Zhang Z, et al. Status of Hypertension in China: Results From the China Hypertension Survey, $2012-2015$. Circulation. 2018;137(22):2344-56.

11. Ettehad D, Emdin CA, Kiran A, Anderson SG, Callender T, Emberson J, et al. Blood pressure lowering for prevention of cardiovascular disease and death: a systematic review and meta-analysis. Lancet. 2016;387(10022):957-67.

12. Ciccacci F, Majid N, Petrolati S, Agy M, Massango C, Orlando S, et al. Hypercholesterolemia and related risk factors in a cohort of patients with diabetes and hypertension in Maputo, Mozambique. The Pan African medical journal. 2021;38:102.

13. Virani SS, Alonso A, Aparicio HJ, Benjamin EJ, Bittencourt MS, Callaway CW, et al. Heart disease and stroke statistics-2021 update: a report from the American Heart Association. Circulation. 2021;143(8):e254-743.

14. Islami F, Sauer AG, Gapstur SM, Jemal A. Proportion of cancer cases attributable to excess body weight by US state, 2011-2015. JAMA Oncol. 2019;5(3):384-92.

15. LeBlanc ES, Patnode CD, Webber EM, Redmond N, Rushkin M, O'Connor EA. Behavioral and pharmacotherapy weight loss interventions to prevent obesity-related morbidity and mortality in adults: updated evidence report and systematic review for the US Preventive Services Task Force. Jama. 2018;320(11):1172-91.

16. Kyrgiou M, Kalliala I, Markozannes G, Gunter MJ, Paraskevaidis E, Gabra H, et al. Adiposity and cancer at major anatomical sites: umbrella review of the literature. Bmj. 2017;356.

17. Hamman RF, Wing RR, Edelstein SL, Lachin JM, Bray GA, Delahanty L, et al. Effect of weight loss with lifestyle intervention on risk of diabetes. Diabetes Care. 2006;29(9):2102-7.

18. Fazliana M, Liyana AZ, Omar A, Ambak R, Nor NSM, Shamsudin UK, et al. Effects of weight loss intervention on body composition and blood pressure among overweight and obese women: findings from the MyBFF@ home study. BMC Womens Health. 2018;18(1):25-32.

19. Watts GF, Ooi EM, Chan DC. Demystifying the management of hypertriglyceridaemia. Nat Rev Cardiol. 2013;10(11):648-61.

20. Wing RR, Lang W, Wadden TA, Safford M, Knowler WC, Bertoni AG, et al. Benefits of modest weight loss in improving cardiovascular risk factors in overweight and obese individuals with type 2 diabetes. Diabetes Care. 2011;34(7):1481-6.

21. Van Zyl S, van Rooyen FC, Joubert G, Kruger WH, Walsh CM. A Comparison of the Socio-Behavioral-Metabolic Risk Profiles and Associated Factors for Chronic Diseases of Lifestyle in Urban and Rural Communities in Central South Africa. Front Public Health. 2020;8.

22. Dorairaj P, Shuchi A, Gaziano T, Mbanya J, Wu Y, Nugent R. Disease control priorities: volume 5. Cardiovascular, respiratory, and related disorders. Disease control priorities: volume 5 Cardiovascular, respiratory, and related disorders. 2017(Ed. 3).

23. WHO. WHO package of essential noncommunicable (PEN) disease interventions for primary health care. 2020.

24. WHO. Noncommunicable diseases country profiles 2018. World Health Organization; 2018.

25. World Health Organization. Regional Office for the Eastern M. Noncommunicable diseases in the Eastern Mediterranean Region. Cairo: World Health Organization. Regional Office for the Eastern Mediterranean; 20162016.

26. Peykari N, Hashemi H, Dinarvand R, Haji-Aghajani M, Malekzadeh R, Sadrolsadat A, et al. National action plan for non-communicable diseases prevention and control in Iran; a response to emerging epidemic. J Diabetes Metab Disord. 2017;16(1):1-7.

27. Tabrizi JS, Farahbakhsh M, Sadeghi-Bazargani H, Nikniaz L. Prevention and control of non-communicable diseases in Iranian population: life style promotion project phase II: study protocol. Iran J Public Health. 2018;47(9):1397.

28. Hamzehkhani MS, Zahiri M, Haghighizadeh MH, Dehcheshmeh NF. Evaluating the quality of Iran's Package of Essential Non-communicable (IraPEN) disease in the Eastern Health Center of Ahvaz: Viewpoints of the referring patients. Arch Pharm Pract. 2020;1:62.

29. Asadi-Aliabadi M, Tehrani-Banihashemi A, Mirbaha-Hashemi F, Janani L, Babaee E, Karimi SM, et al. Evaluating the impact of results-based motivating system on noncommunicable diseases risk factors in Iran: Study protocol for a field trial. Med J Islam Repub Iran. 2021;35:66.

30. SCl. Population and Housing Censuses Statistical Center of Iran2016 [Available from: https://www.amar.org.ir/english/Population-and-HousingCensuses.

31. Parliament. The fifth development plan act: The Parliament of Iran 2010 [Available from: http://rc.majlis.ir/fa/law/print_version/790196. 
32. Djalalinia S, Modirian M, Sheidaei A, Yoosefi M, Zokaiee H, Damirchilu B, et al. Protocol design for large-scale cross-sectional studies of surveillance of risk factors of non-communicable diseases in Iran: STEPs 2016. Arch Iran Med. 2017;20(9):-

33. MOHME. National action plan for non-communicable diseases prevention and control in Iran 2015-2025: Iranian National Committee for NCDs Prevention and Control; 2015 [Available from: https://iums.ac.ir/files/vch/files/sanad_meli.pdf.

34. CBI. Monthly economic indicators and statistics: Central bank of Islamic Republic of Iran; 2019 [Available from: https://www.cbi.ir/page/19712.aspx.

35. WHO. Hypertension. World Health Organization; 2021 [Available from: https://www.who.int/news-room/fact-sheets/detail/hypertension.

36. NHLBI. High Blood Cholesterol - What You Need to Know: NHLBI PUBLICATIONS AND RESOURCES; 2005 [Available from: https://www.nhlbi.nih.gov/health-topics/all-publications-and-resources/high-blood-cholesterol-what-you-need-know.

37. CDC. Defining Adult Overweight \& Obesity: Centers for Disease Control and Prevention; 2021 [Available from: https://www.cdc.gov/obesity/adult/defining.html.

38. Bertrand M, Duflo E, Mullainathan S. How much should we trust differences-in-differences estimates? The Quarterly journal of economics. 2004;119(1):249-75.

39. AZIZI F, Hadaegh F, KHALILI D, Esteghamati A, HOSSEIN PF, Delavari A, et al. Appropriate definition of metabolic syndrome among Iranian adults:. report of the Iranian National Committee of Obesity; 2010.

40. Chudowolska-Kiełkowska M, Małek $Ł A$. A nurse-led intervention to promote physical activity in sedentary older adults with cardiovascular risk factors: A randomized clinical trial (STEP-IT-UP study). Eur J Cardiovasc Nurs. 2020;19(7):638-45.

41. Ruotsalainen $H$, Kyngäs $H$, Tammelin T, Kääriäinen M. Systematic review of physical activity and exercise interventions on body mass indices, subsequent physical activity and psychological symptoms in overweight and obese adolescents. J Adv Nurs. 2015;71(11):2461-77.

42. Gao Y, Griffiths S, Chan EY. Community-based interventions to reduce overweight and obesity in China: a systematic review of the Chinese and English literature. J Public Health. 2008;30(4):436-48.

43. Moores C, Bell L, Miller J, Damarell R, Matwiejczyk L, Miller M. A systematic review of community-based interventions for the treatment of adolescents with overweight and obesity. Obes Rev. 2018;19(5):698-715.

44. Ibrahim N, Ming Moy F, Awalludin IAN, Mohd Ali Z, Ismail IS. Effects of a community-based healthy lifestyle intervention program (Co-HELP) among adults with prediabetes in a developing country: a quasi-experimental study. PloS one. 2016;11(12):e0167123.

45. Rodriguez FA, Community-Based Intervention for Reducing Hypertension and Cardiovascular Disease Risk: NEJM Journal Watch; 2019 [Available from: https://www.jwatch.org/na49844/2019/09/02/community-based-intervention-reducing-hypertension-and.

46. Lin A, Zhang G, Liu Z, Gu J, Chen W, Luo F. Community-based lifestyle intervention for reducing blood pressure and glucose among middle-aged and older adults in China: a pilot study. Int J Environ Res Public Health. 2014;11(11):11645-63.

47. Jafar TH, Hatcher J, Poulter N, Islam M, Hashmi S, Qadri Z, et al. Community-based interventions to promote blood pressure control in a developing country: a cluster randomized trial. Ann Intern Med. 2009;151(9):593-601.

48. Sahli J, Maatoug J, Harrabi I, Fredj SB, Dendana E, Ghannem H. Effectiveness of a community-based intervention program to reduce hypertension prevalence among adults: results of a quasiexperimental study with control group in the region of Sousse, Tunisia. Glob Heart. 2016;11(1):131-7.

49. Lotfaliany M, Mansournia MA, Azizi F, Hadaegh F, Zafari N, Ghanbarian A, et al. Long-term effectiveness of a lifestyle intervention on the prevention of type 2 diabetes in a middle-income country. Sci Rep. 2020;10(1):1-10.

50. Osborn D, Burton A, Hunter R, Marston L, Atkins L, Barnes T, et al. Clinical and cost-effectiveness of an intervention for reducing cholesterol and cardiovascular risk for people with severe mental illness in English primary care: a cluster randomised controlled trial. Lancet Psychiatry. 2018;5(2):145-54.

51. Allen JK, Dennison-Himmelfarb CR, Szanton SL, Bone L, Hill MN, Levine DM, et al. Community Outreach and Cardiovascular Health (COACH) Trial: a randomized, controlled trial of nurse practitioner/community health worker cardiovascular disease risk reduction in urban community health centers. Circ Cardiovasc Qual Outcomes. 2011;4(6):595-602.

52. Coodley GO, Jorgensen M, Kirschenbaum J, Sparks C, Zeigler L, Albertson BD. Lowering LDL cholesterol in adults: a prospective, community-based practice initiative. Am J Med. 2008;121(7):604-10.

53. Minneboo M, Lachman S, Snaterse M, Jørstad HT, Ter Riet G, Boekholdt SM, et al. Community-based lifestyle intervention in patients with coronary artery disease: the RESPONSE-2 trial. J Am Coll Cardiol. 2017;70(3):318-27.

54. Schuit AJ, Wendel-Vos GC, Verschuren WM, Ronckers ET, Ament A, Van Assema P, et al. Effect of 5-year community intervention Hartslag Limburg on cardiovascular risk factors. Am J Prev Med. 2006;30(3):237-42.

55. Cai R, Chao J, Li D, Zhang M, Kong L, Wang Y. Effect of community-based lifestyle interventions on weight loss and cardiometabolic risk factors in obese elderly in China: A randomized controlled trial. Exp Gerontol. 2019;128:110749.

56. Keyserling TC, Samuel-Hodge CD, Pitts SJ, Garcia BA, Johnston LF, Gizlice Z, et al. A community-based lifestyle and weight loss intervention promoting a Mediterranean-style diet pattern evaluated in the stroke belt of North Carolina: the Heart Healthy Lenoir Project. BMC Public Health. 2016;16(1):1-22.

57. Puska P. From Framingham to North Karelia: from descriptive epidemiology to public health action. Prog Cardiovasc Dis. 2010;53(1):15-20.

58. Higginbotham N, Heading G, McElduff P, Dobson A, Heller R. Reducing coronary heart disease in the Australian Coalfields: evaluation of a 10-year community intervention. Soc Sci Med. 1999;48(5):683-92.

59. Puska P. Successful prevention of non-communicable diseases: 25 year experiences with North Karelia Project in Finland. Public Health Med. 2002;4(1):5-7. 
60. Alexander MR. How does physical activity and/or weight loss affect blood pressure (BP)?: Medscape; 2019 [Available from: https://www.medscape.com/answers/241381-7691/how-does-physical-activity-andor-weight-loss-affect-blood-pressurebp\#: :text=Regular\%20aerobic\%20physical\%20activity\%20can,with\%20moderately\%20intense\%20physical\%20activity.

61. Staessen J, Fagard R, Amery A. The relationship between body weight and blood pressure. J Hum Hypertens. 1988;2(4):207-17.

62. Lindström T, Kechagias S, Carlsson M, Nystrom FH, Group FFS. Transient increase in HDL-cholesterol during weight gain by hyperalimentation in healthy subjects. Obesity. 2011;19(4):812-7.

63. Nurdiantami Y, Watanabe K, Tanaka E, Pradono J, Anme T. Association of general and central obesity with hypertension. Clin Nutr. 2018;37(4):125963.

64. Seravalle G, Grassi G. Obesity and hypertension. Pharmacol Res. 2017;122:1-7.

65. Rosique-Esteban N, Babio N, Díaz-López A, Romaguera D, Martínez JA, Sanchez VM, et al. Leisure-time physical activity at moderate and high intensity is associated with parameters of body composition, muscle strength and sarcopenia in aged adults with obesity and metabolic syndrome from the PREDIMED-Plus study. Clin Nutr. 2019;38(3):1324-31.

66. Langford HG, Davis BR, Blaufox D, Oberman A, Wassertheil-Smoller S, Hawkins M, et al. Effect of drug and diet treatment of mild hypertension on diastolic blood pressure. The TAIM Research Group Hypertension. 1991;17(2):210-7.

67. Gupta R, Guptha S. Strategies for initial management of hypertension. Indian J Med Res. 2010;132(5):531.

68. Harsha DW, Bray GA. Weight loss and blood pressure control (Pro). Hypertension. 2008;51(6):1420-5.

69. Record NB, Onion DK, Prior RE, Dixon DC, Record SS, Fowler FL, et al. Community-wide cardiovascular disease prevention programs and health outcomes in a rural county, 1970-2010. Jama. 2015;313(2):147-55.

70. WHO. Global Action Plan for the Prevention and Control of NCDs 2013-2020 World Health Organization; 2013 [Available from: https://www.who.int/publications/i/item/9789241506236.

71. Rahbar M, Raeisi A, Chowdhury Z, Javadi D. Iran's Community Health Worker Program. 2020.

72. Magkos F, Yannakoulia M, Chan JL, Mantzoros CS. Management of the metabolic syndrome and type 2 diabetes through lifestyle modification. Annu Rev Nutr. 2009;29:223-56.

73. Pérez-Martínez P, Mikhailidis DP, Athyros VG, Bullo M, Couture P, Covas MI, et al. Lifestyle recommendations for the prevention and management of metabolic syndrome: an international panel recommendation. Nutr Rev. 2017;75(5):307-26.

74. Wing RR, Goldstein MG, Acton KJ, Birch LL, Jakicic JM, Sallis JF, et al. Behavioral science research in diabetes: lifestyle changes related to obesity, eating behavior, and physical activity. Diabetes Care. 2001;24(1):117-23.

75. Kishk NA, Shahin Y, Mitri J, Turki Y, Zeidan W, Seita A. Model to improve cardiometabolic risk factors in Palestine refugees with diabetes mellitus attending UNRWA health centers. BMJ Open Diabetes Res Care. 2019;7(1):e000624.

76. Azizi F, Mirmiran P, Momenan AA, Hadaegh F, Habibi Moeini A, Hosseini F, et al. The effect of community-based education for lifestyle intervention on the prevalence of metabolic syndrome and its components: tehran lipid and glucose study. Int J Endocrinol Metab. 2013;11(3):145-53.

77. Blonde L, Dempster J, Gallivan JM, Warren-Boulton E. Reducing cardiovascular disease risk in patients with diabetes: a message from the National Diabetes Education Program. J Am Acad Nurse Pract. 2006;18(11):524-33.

78. Lester H, Schmittdiel J, Selby J, Fireman B, Campbell S, Lee J, et al. The impact of removing financial incentives from clinical quality indicators: longitudinal analysis of four Kaiser Permanente indicators. Bmj. 2010;340.

79. Foskett-Tharby R, Nick H, Gill P. Pay for performance and the management of hypertension. J Transl Int Med. 2016;4(1):14.

80. Serumaga B, Ross-Degnan D, Avery AJ, Elliott RA, Majumdar SR, Zhang F, et al. Effect of pay for performance on the management and outcomes of hypertension in the United Kingdom: interrupted time series study. Bmj. 2011;342.

\section{Figures}




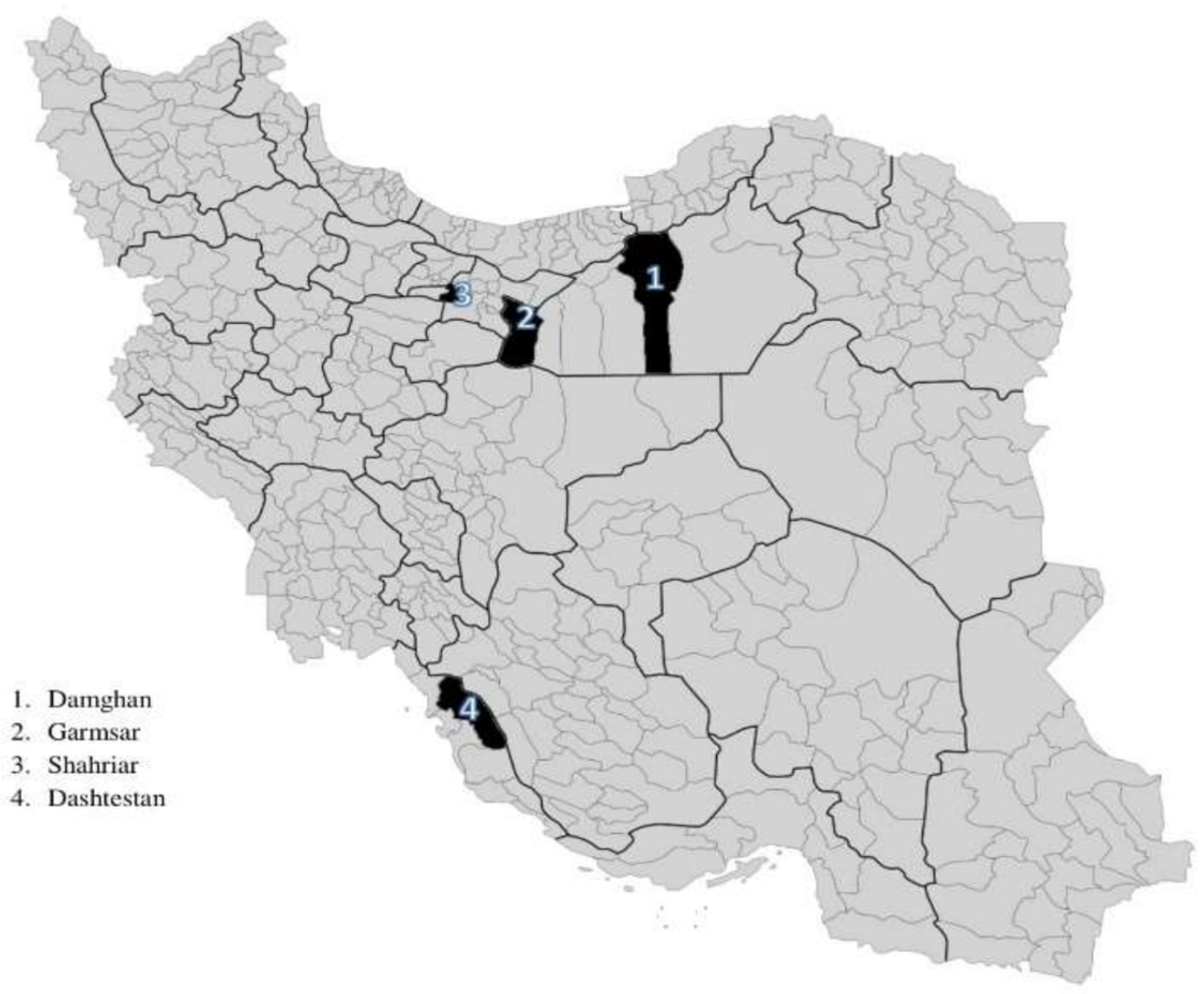

Figure 1

Districts of intervention and no intervention in IRPONT study

Source: This is an edited version of the map downloaded from

https://en.wikipedia.org/wiki/List_of_cities_in_Iran_by_province\#/media/File:Iran_Counties_by_Population_(2021).svg 


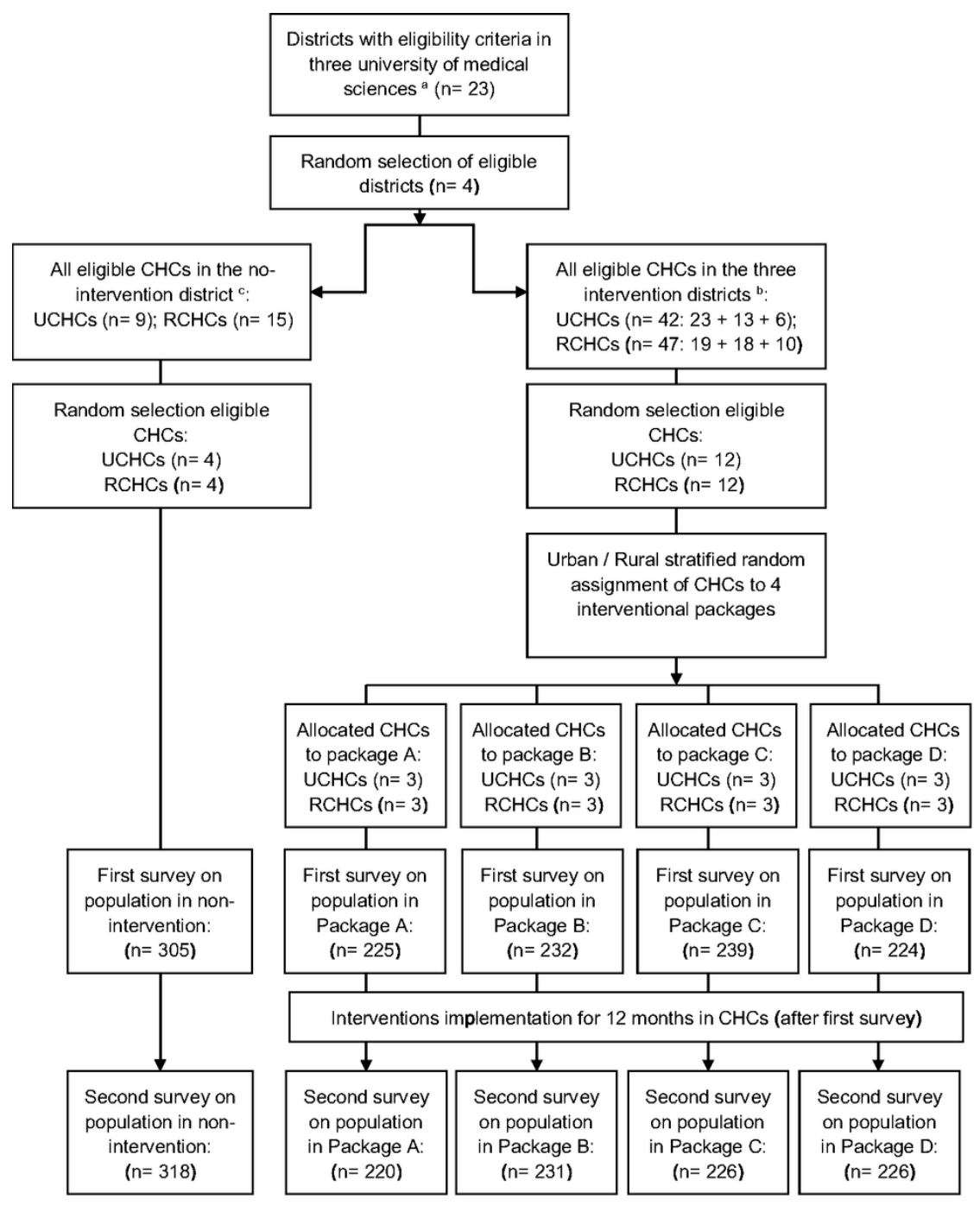

Figure 2

CONSORT flow diagram

Note: Analysed based on population in first and second surveys.

a These three universities are located in three provinces of Tehran, Semnan, and Bushehr in Iran, and one of the main tasks of them are to provide primary health services to the covered population.

b Shahriar, Dashtestan, and Damghan.

${ }^{\mathrm{c}}$ Garmsar.

\section{Supplementary Files}

This is a list of supplementary files associated with this preprint. Click to download.

- CONSORTchecklist.docx 